\title{
Assignment of the Nominative Case in Jussive Structures in Arabic Syntax: A Minimalist View
}

\author{
Atef Mustafa Jalabneh \\ Department of English, Faculty of Languages and Translation, King Khalid University, Saudi Arabia \\ Email: atefjalabneh@hotmail.com
}

\begin{abstract}
The objective: this work is meant to assign the nominative case to the subject of the jussive structure in Arabic syntax in the absence of a case assignor at all levels of syntax. The methodology: to give a justifiable solution to this problem, the researcher refers to Chomsky's (1981 and 1995) and Radford (1988) theoretical views on this issue. The results: though there is no overt tense to function as a case assignor to the subject, the jussive sentence is grammatical. It was claimed by the traditional grammarians that the subject is in the nominative due to the occurrence of the final overt morphological realizations. The conclusion: an overt subject $N$ " or covert one liable to case cannot occur in a sentence without being governed by a case assignor; the researcher could find out that the nominative case assignor is the empty [T].
\end{abstract}

Index Terms - nominative case, assignor, jussive, nonfinite, pro, tense, NP-movement

\section{INTRODUCTION}

Traditional Arabic Grammarians posited three different cases; they are visible as follows: (i) the nominative case, (ii) the objective case (a cover-term for accusative and dative cases) and (iii) the genitive case (oblique or prepositional cases). Haque (1984) argued that though Traditional Arabic Grammarians claimed that the concept of case is the relation of a noun or pronoun with some other word or words in the sentence, by case they mean the overt morphological endings of the case - markings and not the grammatical relation which is established between the NP and a verb or some other constituents in the sentence at an abstract level (p. 464-469). It becomes evident that a look into their claim further shows that the three cases in Arabic that they talked about are solely based on the case-endings and not on structural relations established in the sentence.

Jalabneh (2005) argued that the subject DP in any nominal sentence in the structure [DP, TP] is the focus, and it is in most situations in the nominative case. This case in particular is checked by $\mathrm{T}$ whenever a verb is overt in a sentence. However, if the same DP occurs in the structure [DP, AP, DP, PP], the nominative case is checked by the twin Agrs. This result is achieved because there is no $\mathrm{T}$ at the output $(\mathrm{p}, 5)$.

Jalabneh (2011a) argued that Arabic is a pro-drop language in which the entity pro is liable to case. assignment. Pro is covert at LF; however, the sentence is grammatically good. This category must be governed to get the nominative case by the case assignor, namely, INFL/Agrs (p, 576).

Jalabneh (2010) argued that pro occurs as the subject of subjunctive clauses in which the entity in question is assigned the nominative case by the empty [e] of INFL] in the maximal projection [Spec, I"]. This is due to the fact that such structures do not have overt $\mathrm{T}$ though there are finite clauses ( $\mathrm{p}, 98-100)$.

Jalabneh (2011b) confirmed that $\mathrm{T}$ is a formal feature in subjunctive structures at all levels of syntax. It is labeled as the empty category [e] which is able to check the nominative case to D" after the phrase moves to the position of [Spec, T"] $(\mathrm{p}, 7)$.

Rizzi (1982) argued that, in Italian, the dropped subject is visible with clitics because it is rich in agreement features. Pro occurs in a main clause and is governed by INFL. Thus, it is specified at LF by the feature [+ pronominal]. INFL absorbs the nominative case because of case filter and assign the nominative case to pro.

Picallo (1984) argued that, in Catalan, INFL is the proper governor for the nominative case assignment to pro of a finite clause. The category pro is an empty non-anaphoric pronominal element which receives this particular case, and it is recoverable in feature specification by means of agreement features of the verb.

Haegeman (1991) argued that null subject has the properties [+pronominal, -anaphoric]. INFL is the only property that allows and identifies pro. Agreement features recover the dropped subject with which they co-indexed.

Anders (2005) argued that pro is specified but unpronounced pronouns that assign a case by the misinterpreted Agrs. Null bound pronouns and null generic pronouns in partial null subject languages like Finish are D-less; thus, they are pros in consistent null subject languages with Agrs such as Spanish and Greek. First and second person pros are deleted in Finish. Null pronouns in languages without Agrs such as Chinese and Japanese are only true instances of pros that is a minimally specified null noun.

Fehri (1987) argued that non pronominal affixes are non referential affixes but agreement markers whose sole function is to encode the subject gender on the verb. The difference between male and female null subject is obvious with the agreement features attached to the verb used. 


\section{PROBLEM OF THE STUDY}

The problem of this study is that the subject of the finite jussive structure is in the nominative case without having a case assignor. This issue pushed me to find out the reason behind the grammaticality of the sentence which should not be and to find out nature of this case assignor.

\section{OBJECTIVES AND QUESTIONS OF THE STUDY}

The objectives of this research are to find correct solutions to the reasons behind the grammaticality of the jussive sentence in the absence of the case assignor to the subject. To solve the issue of case assignment in jussive structures, the following questions are being asked.

1. What is the exact case assignor for the nominative case in jussive?

2. How is the subject in the nominative case without a case governor?

3. Is there any kind of relation between jussive particles and case assignment?

\section{THEORETICAL VIEWS ON CASE THEORY}

Chomsky (1981, 1982, 1986 \& 1995) theoretically argued that, in the case-theory, a lexical N" has to satisfy three conditions in order to be assigned a case. The conditions are: Every phonetically realized N" must be assigned a case. In other words, for an N" to be assigned a case, it must be overt in the sentence. An N" that belongs to the empty categories, namely, (PRO and trace) cannot have a case. This is covered by the case-filter which says that any lexical NP which does not have a case (covert or overt) is ungrammatical. The second condition is that there must be a caseassigner to assign the case to the lexical N". Just as in English [T], verbs and prepositions are case-assigners. Each case assigner occurs as the head of a phrasal category that dominates the $\mathrm{N}$ " to which it assigns a case. [T] is the caseassigner of the subject N" even though it is not the head of that phrasal category. For an N" to be assigned a case, it must be in a particular syntactic environment which is headed by the case-assigner. For instance, verbs mark the accusative case to their complement N"s i.e., [N", V"], prepositions assign the oblique cases to every N" which occurs after them, [N", P']. The nominative case, in particular, is assigned to the subjects of the finite clauses by the [T] which has been identified as its case-assigner. The third condition for the assignment of case is that the N" that is to be assigned a case must be governed by its case-assigner. As we have already noted, according to the case theory the caseassigners are verbs, prepositions and T. This condition is relying on the distribution of N"s and their relations with the governors in the sentence. In other words, [T] assigns the nominative case to its subject N", verbs assign the accusative case to their complement N"s which they govern; and prepositions assign the oblique case to their complement N"s which they govern. The government theory makes a clear distinction between the governor and the governed N". Governors are either the lexical items verbs and prepositions and the inflection [T]; they must be the head of their phrases that most immediately involves the governed N" to which a case is assigned. The government theory asserts that the case-assignment takes place only if the case-assigner and the governed N" to which a case is assigns bear a structural relation to one another known as a government. The concept of government and command must be local for case assignment.

He (1981 - 1995) also argued that the distinction between finite and non finite is related to the nature of [T], which has the value [ \pm Tense], where [+Tense] stands for finite and [- Tense] for infinitival. Thus, the former consists of $\mathrm{C}$ and $\left.\mathrm{T}^{\prime \prime}\right]$ while the latter has only [T"]. C" within X-bar syntax is projected to account for the argument structure of a predicate and account for the fronted wh/that-phrases, the complementizer 'for' and inverted auxiliaries that move to $\mathrm{C}$ node. A full clause is headed by a complementizer $\mathrm{C}$; hence the structure is a CP satisfying X-bar theory. $\mathrm{C}$ may have a specifier but must have a complement which is T" which has the complement V". A clause is typically has the structure [CP Spec [ [C C [IP Spec [I I VP]]]]. Specifier of [Spec, CP] is optional and it is a non argument position. The Extended Projection Principle states that [Spec, IP] is obligatory position. Spec is the subject of T" and thus it is an argument position. [Spec, CP] is meant either for moved and in situ of both wh-words and relative clauses or for available complementizers such as 'that, 'for' and 'whether'.

Radford (1988) propagates Chomsky's (1981-1986) theoretical views of case assignment, particularly, theory the of [T] and further argues that the verb of the indicative of English can take the present tense -(e)s and the past tense -(e)d inflections in an appropriate context; whereas, the verb in the mood cannot and must remain invariable. What makes the mood structure different from the indicative is that the former does not contain any overt tense and agreement marking and still it is regarded a finite clause. This claim is defended on both grounds: (i) Universalist and (ii) Particularist. On Universalist ground, it is argued that in languages which are rich in inflectional system other than English, mood clauses do indeed turn out to be inflected. For instance, in Spanish, Romanian, Italian, etc. the mood verb is inflected in both tense and agreement features simultaneously. In other words, the feature $3^{\text {rd }}$ person, singular present subjunctive is overt for the present form and the $3^{\text {rd }}$ person singular past subjunctive is overt for the past form. As mood clauses are clearly finite in nature in such languages, it is argued that on universal grounds it is possible to regard them finite in English also. On Particularist grounds, English mood clauses are treated finite as they share certain morpho-syntactic properties in common with indicative clauses which differentiate them from non-finite clauses. For instance, (i) neither subjunctive nor indicative clauses can be constructed without overt subjects; whereas, nonfinite clauses can indeed be 
subjecless. (ii) Both the clauses (unlike nonfinite clauses) must case-assign to the overt subjects they contain with the nominative case. The subject of either an indicative or the mood is always assigned the nominative case by [I/or $\mathrm{T}$ (henceforth T]. The question arises here is that: how is the nominative case assigned to the subject of the mood without having [T] constituent as per X-bar syntax?

Theoretically, although a finite [T] is overtly or covertly inflected for tense and agreement features, the nonfinite [T] lacks such features. It is also argued that finite clauses that contain an overt [C] in fact must have a finite [T]; however, a clause that contains a nonfinite [C] requires a nonfinite [T]. But contradicted to the former logic is the mood clause in which there is [C] but it does not contain an overt finite [T]. An assumption given by Radford (1988, p. 307) says "Any clause which contains C contains a compatible I/". Thus, mood clauses in English require an overt complementizer and any clause that contains [C] also contains an [T], then it follows that mood complement clause contains [T] node. And since $[\mathrm{T}]$ constituent does not appear overtly in such structures, the obvious solution to be followed over here is that the mood has an empty [T]. This assumption leads to a final universal conclusion that says all clause that have [T] can either be filled by tense if finite, by 'to' if nonfinite or left empty. The empty [T] helps to achieve the structural account of the nominative case checking. In other words, a N" which is a sister of a finite [T] must assign the nominative case in accordance with the case-filter as well as the adjacency parameter.

The above theoretical views will be used for the assignment of the nominative case in jussive mood in Arabic syntax in this study.

\section{The Assignment of the Nominative Case in Jussive}

As far as the jussive structure in Arabic is concerned, it is a kind of mood in addition to subjunctive and energetic forms of the imperfective. The subjunctive mood is a universal concept; however, the other two structures are somehow specific to Arabic. Syntactically, Arabic has a number of jussive entities of different natures; if any one of them precedes the verb of imperfective, certain syntactic issues have to happen. The entities are represented by: (i) lam ' not', (ii) lamma ' not', (iii) li 'let', (iv) la 'not', (vii) 'in 'if', (viii) man 'who', (ix) ma 'whatever', (x) mahma 'whatever', (xi) 'aiyana 'when', (xii), $h \square$ aithuma 'whenever', (xiii) kaifama ' however', (xiv) 'aina 'where' and (xv) 'nna ' wherever'. Each entity has its own syntactic as well as semantic properties; however, the focus of this study is to find whether there is any kind of syntactic relation with case assignment in this type of sentence in which the occur. To check the nominative case, let us look at (1).

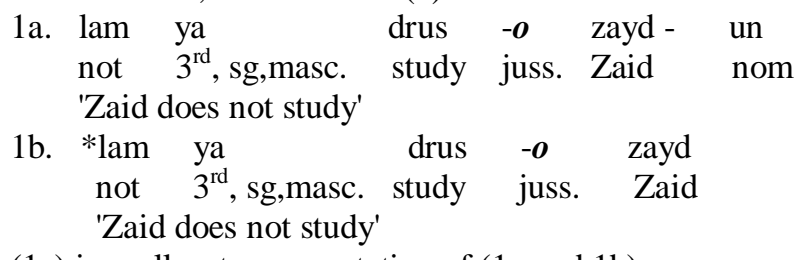

(1c) is spell-out representation of (1a and $1 b)$. 


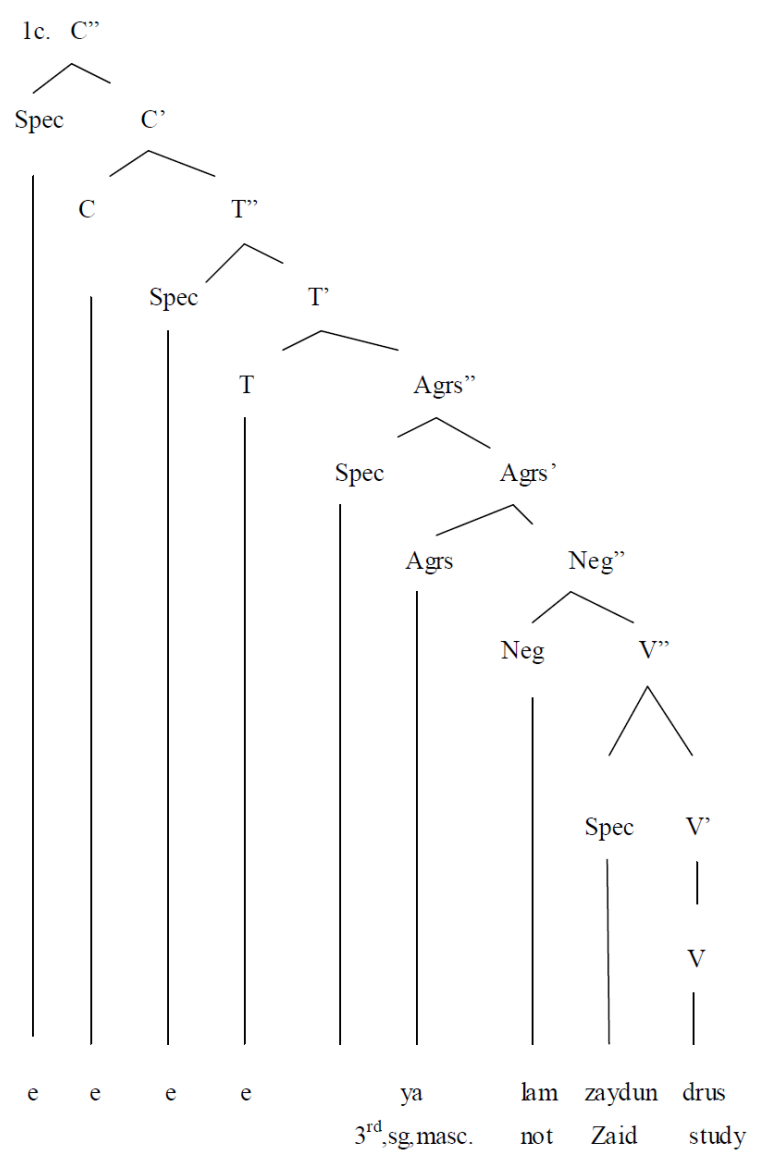

In (1c), [e] stands to an empty category. The subject N" zaydun 'Zaid' is overt and occupies the position of [Spec, V']. As it is in a caseless position, it has to move to [Spec, Agrs"] to be checked the nominative case feature by the governor [T] which is filled by the category [e]. This empty category of [T] is the true case assignor for the nominative and it has the same power of the overt [T] of the indicative. The negative item lam occupies [Neg, Neg'] and it negates the scope of [V']. There are three types of movements involved: (i) NP- movement which took place from [Spec, V'] to [Spec, T], the negative entity- movement which has to be from [Neg, Neg'] to [Spec, C'] to initiate the jussive at LF and V- movement which is from [V, V'] to [Agrs, Agrs'] to check agreement subject features of $3^{\text {rd }}$, sg, masc. and becomes yadrus 'study', then the position of [T, T'] to check the empty tense and becomes yadrus + tense 'study' and in a final cyclic movement, it moves to the position of [C, C'] at LF as in (1d). If (1c) is compared to (1b), the latter is ungrammatical because the subject is left without the assignment of the nominative case by the empty [T]. 


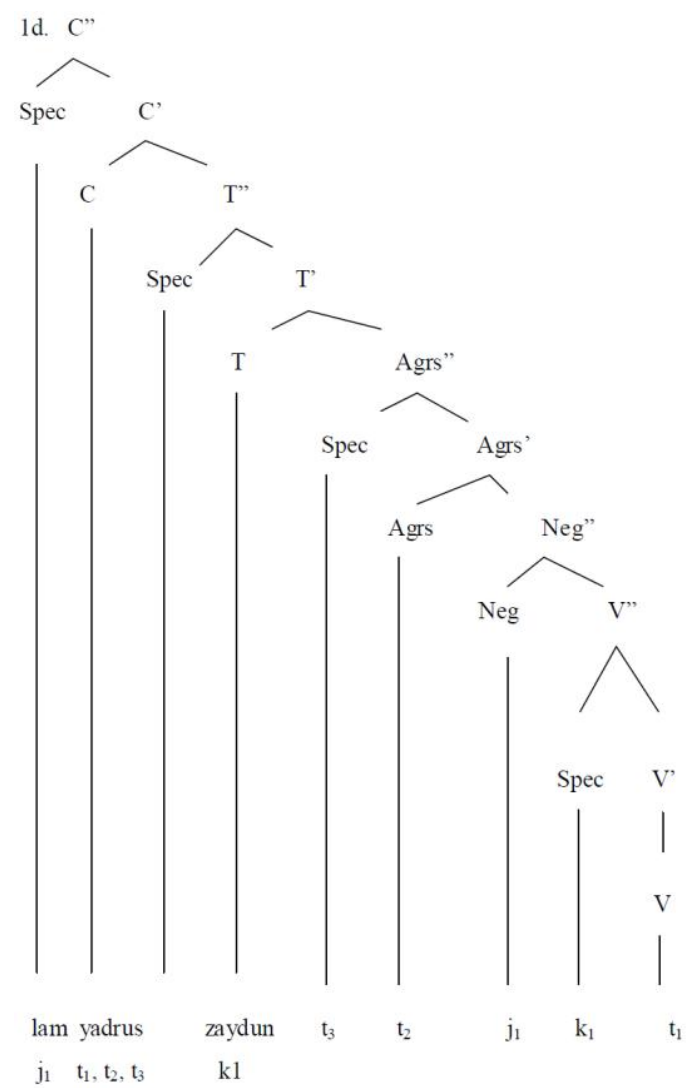

Suppose the subject is pro, then the assignment of the nominative case is as in (2).

2a. la ta- lq $\quad-a \quad d \square$ aifa- ka

not $2^{\text {nd }}, \mathrm{sg}$,masc meet juss. guest your

'Do not meet your guest

(2b) is spell-out for (2a): 


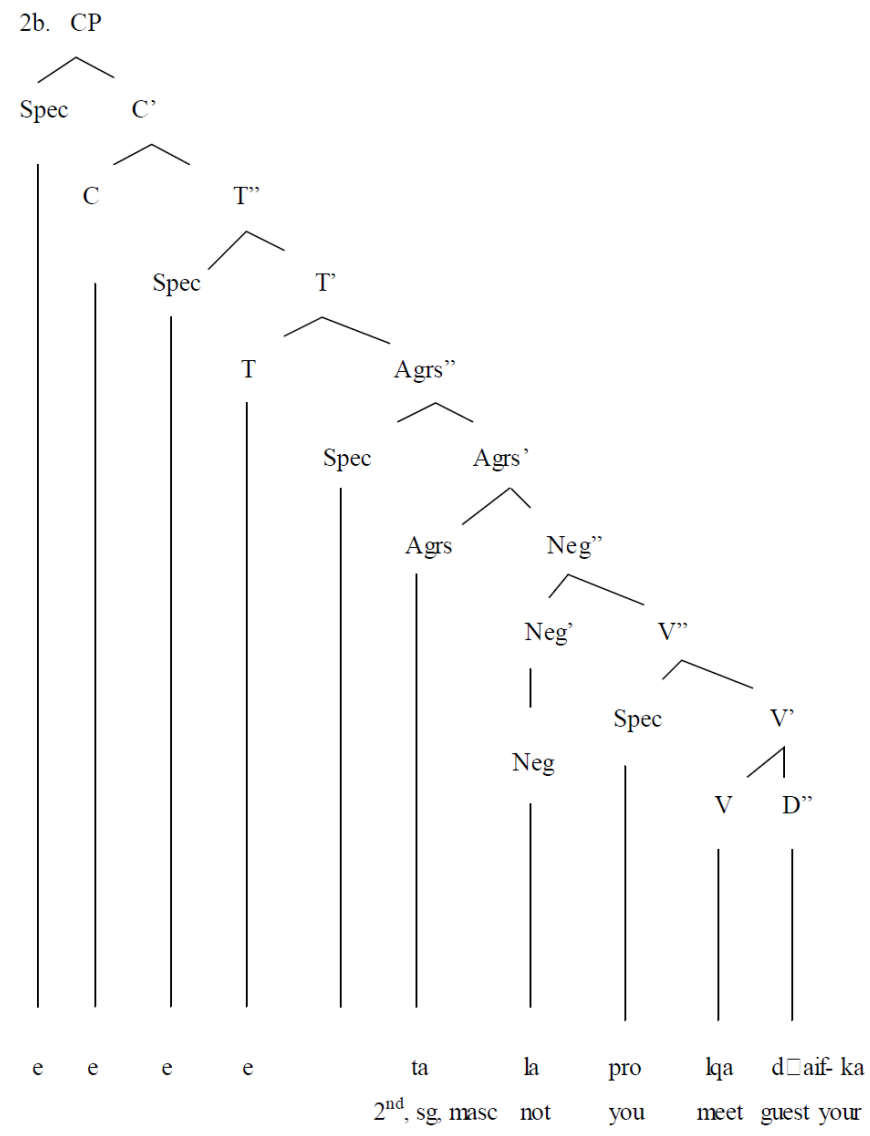

In (2b), the empty category pro occupies the position of [Spec, V"] at spell-out; as it is in a caseless position, it must move to the position of [Spec, T"] to be checked the nominative case by the governor [T]. This pro is specified by the Agrs as $2^{\text {nd }}$, sg and masc. for correct interpretation at LF; it is deleted at interface before LF. The negative item of jussive $l a$ 'not' moves to [Spec, C']. While the verb lqa 'meet' moves to [Agrs, Agrs'] to check ta to become talga 'meet', to [T, T'] to check the empty tense feature and remains talga; then, in a final cyclic movement, it moves to. [C, C'] to initiate the sentence.

To sum up, though [T, T] is filled with empty tense, in (1 and 2), the subject position checks the nominative case feature. The polarity negative items lam and la 'not' as specimens of jussive have the C" scope of negation; thus, they occupy the [Spec, C'] position at LF. It is argued that empty [T] is as strong as overt [T]. Agrs specifies the over as well as the covert subject for correct interpretation of Arabic sentence at LF after being attached to V. Agrs is strong feature and cannot be deleted at all levels of syntax. Thus, it helps to understand the significance of jussive mood in Arabic syntax in a proper manner.

\section{CONCLUSIONS}

The question of the assignment of the nominative case to the subject of the jussive structure is a controversial issue due the absence of the governor [T] though it is a finite clause as that of the indicative. The issue is solved with the help of Chomsky's case theory (1981-1995) and the evolvement of Radford's theory of empty tense (1988) to deal with this issue. It was noticed that the tense system of Arabic in mood is entirely empty and it has no sign of visibility; however, if compared to Agrs, the latter is morphologically strong. Therefore, if the subject is overt or covert, it is specified by Agrs features at all levels of syntax. Theoretically, [T] is amalgam of both [T] and Agrs; but, [T] is prior to check the nominative case. Thus, in (1), the overt subject is assigned the nominative case by the empty [T]; however, in (2), the subject is covert and is assigned the same case by the same case assignor. To get correct LF interpretation, the jussive particle must move to [Spec, C'] and the verb to [C, C']. If the subject is covert, it remains in the position of [Spec, T"]; however, if it is pro, it lands in the same position for case checking; but, it has to be omitted at the interface level. Thus, case theory is a mechanism that accounts for the assignment of case to the subject and regulates the grammaticality of the sentence before LF.

\section{APPENDix 1 Transliteration Symbols of ARABiC CONSONANTS PHONEMES}




\begin{tabular}{|c|c|c|c|}
\hline Arabic & Transliteration & Arabic & Transliteration \\
\hline i & $?$ & ض & $\underline{\mathrm{d}}$ \\
\hline ب & $\mathrm{b}$ & $b$ & $\underline{t}$ \\
\hline$ت$ & $t$ & ظ & $\underline{z}$ \\
\hline 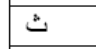 & th & $\varepsilon$ & $\mathrm{c}_{\mathrm{i}}$ \\
\hline ج & $\mathrm{j}$ & $\dot{\varepsilon}$ & gh \\
\hline$\tau$ & $\underline{\mathrm{h}}$ & ف & $\mathrm{f}$ \\
\hline$\dot{\tau}$ & $\mathrm{kh}, \mathrm{x}$ & ق & $q$ \\
\hline د & $\mathrm{d}$ & ك & $\mathrm{k}$ \\
\hline$\dot{j}$ & $\mathrm{dh}$ & J & 1 \\
\hline J & $\mathrm{r}$ & 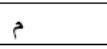 & $\mathrm{m}$ \\
\hline j & $\mathrm{z}$ & ن & $\mathrm{n}$ \\
\hline س & sh & 9 & $\mathrm{w}$ \\
\hline ص ص & $\underline{\mathrm{S}}$ & ي & $\mathrm{y}$ \\
\hline
\end{tabular}

Notice: the researcher used the transliteration symbols in this work .(c.f. Oxford Journal for Islamic Studies)

\section{APPENDIX 2 Transliteration SyMBOLS OF ARABIC Vowels PHONEMES}

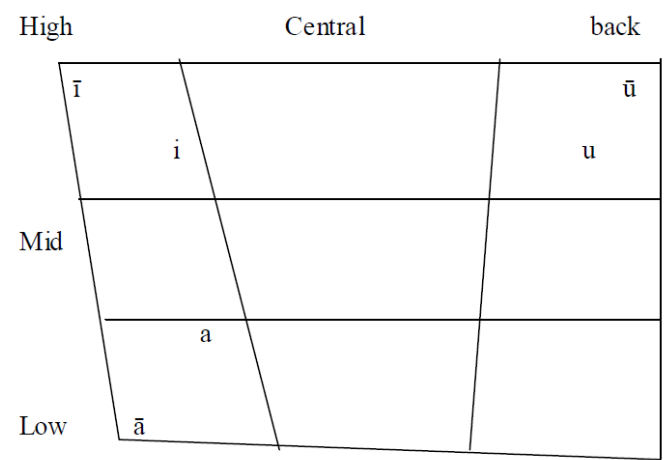

(c.f. Oxford Journal for Islamic Studies)

\section{APPEndix 3 Standard ARABIC Phonetic Symbols of CONSONANTS AS PER IPA}

\begin{tabular}{|c|c|c|c|c|c|c|c|c|c|c|}
\hline bi- & labio- & Inter- & alveolar & & palato- & palatal & velar & uvular & pharyn- & glottal \\
\hline labia & dental & dental & plain & emphati & alveola & & & & geal & \\
\hline nasal $\mathrm{m}$ & - & - & $\mathrm{n}$ & - & - & - & - & - & - & \\
\hline Stop vl - & - & - & $\mathrm{t}$ & $\underline{t}$ & - & - & $\mathrm{k}$ & q & - & $?$ \\
\hline $\mathrm{v} \quad \mathrm{b}$ & - & - & d & $\underline{\mathrm{d}}$ & $\mathrm{d}_{3}$ & - & - & - & - & \\
\hline Frica- & & & & & & & & & & \\
\hline tive $\mathrm{vl}$ - & f & $\theta$ & $\mathrm{S}$ & $\underline{\mathrm{S}}$ & $\int$ & - & - & $\chi$ & $\hbar$ & $\mathrm{h}$ \\
\hline $\mathrm{v}-$ & - & ð & z & $\underline{\partial}$ & - & - & & 6 & $\mathrm{c}_{\mathrm{i}}$ & - \\
\hline Trill & - & - & $\mathrm{r}$ & - & - & - & - & - & - & - \\
\hline Lateral - & - & - & - & 1 & - & - & - & - & - & - \\
\hline Approxi- & & & & & & & & & & \\
\hline mants $\mathrm{w}$ & - & - & - & - & - & $\mathrm{j}$ & & & & \\
\hline
\end{tabular}

Notice: the researchers do not refer to the phonetic symbols but they used merely the transliteration ones while writing the Arabic specimens in the text. The phonetic symbols are listed only for knowledge (c.f, http:/en wikipedia.org/wiki Arabic Phonolgy). 


\section{APPENDIX 4 ABBREVIATIONS}

Agrs: Agreement subject

Agrs": Agreement phrase

C: Complementizer

C": Complementizer phrase

D- : Noun features

Det : Determiner

D": Determiner phrase

INFL: Inflection

Juss.: Jussive

LF: Logical form

Masc.: Masculine

Neg": Negative phrase

Sg.: Singular

Spec: Specifier

T": Tense phrase

T: Tense

V": Verb phrase

$\mathrm{V}$ : Verb

\section{REFERENCES}

[1] Anders, H. (2005). Is there a little pro? Evidence from Finish. Linguistic Inquiry, Vol. (36), No. (4), p. 533-564.

[2] Chomsky, N. (1981). Lectures on government and binding. Dordrecht: Foris Publications.

[3] Chomsky, N. (1982). Some concepts and consequences of the theory of government and binding. Cambridge, Mass.: MIT Press.

[4] Chomsky, N.(1986). Knowledge of language: Its nature, origin and use. New York: Praeger.

[5] Chomsky, N. (1995). The minimalist program. Cambridge: MIT Press.

[6] Fehri, F. (1987). Generalized IP structure, case, and VS word order. Rabat: Faculty of Letters.

[7] Haegeman, L. (1991). Introduction to government and binding theory. Massachusetts Cambridge.

[8] Haque, A. (1984). Brilliant grammar. Dooband, India: Darul Uloom.

[9] Jalabneh, A. (2005). Agr: The nominative/accusative case checker and theta marking regulator in nominal sentences in Arabic syntax: A minimalist view. Jordan Journal of Applied Sciences, vol.8, No.2, pp. 1-18.

[10] Jalabneh. A. (2010). Syntactic analysis of pro in embedded clauses in Arabic syntax: Chomsky (1981-1986) Atlas for Studies and Research, Vol. 5, No. 2, pp. 93-112.

[11] Jalabneh. A. (2011a). Syntactic analysis of pro in independent clauses in Arabic syntax: Government and Binding. Theory and Practice in Language Studies, Vol. 1, No. 6, pp. 572-583.

[12] Jalabneh, A. (2011b). Embedded complementizer phrase subjunctive and features checking: A contrastive study between English, Arabic and German. Accepted for publication and to appear at Damascus University Journal.

[13] Picallo, M. (1984). The infl node and the null subject-parameter. Linguistic Inquiry, Vol, 15, No. 1 pp. 75-102.

[14] Radford, A. (1988). Transformational grammar. Cambridge: University Press.

[15] Rizzi, L. (1982). Issues in Italian syntax. Dordrecht: Foris Publications Holland.

Atef Mustafa Jalabneh was born in Ajloun -Ibbin on Eigh ${ }^{\text {th }}-$ July -1960 . He got his MA, M. Phil and PhD degrees in linguistic from Department of Linguistics/ Delhi University/ India by 1996.

$\mathrm{He}$ is currently occupying an ASSOCIATE PROFESSOR position in Department of English/ Faculty of Languages and Translation/ King Khalid University / Saudi Arabia/ Abha. He published a number of articles such as (i) Jalabneh, A. Topics in EFL Textbooks and the Question of Gender Dominance: A Case Study from Public Schools of Jordan. International Journal of Language Society and Culture. Issue.28. 2009 and (ii) Jalabneh, A (2011) Assimilation of Segments in Modern Standard Arabic: Schane's (1973) Views on Generative Phonology. Dirasat, Human and Social Sciences, Vol. 38, No.1. January, 2011. His basic fields of interests are syntax, semantics, phonology and phonetics.

Dr Jalabneh is currently a foreign coordinator for international affairs/research center for Higher Studies in King Khalid University/ Saudi Arabia. 